\title{
Study on Characteristics of Chemokine CXCL10 Gene Cloned from cDNA Expression Library of Ujumqin Sheep
}

\author{
P. F. Hu, ${ }^{1}$ X. C. Li, ${ }^{1}$ N. Lei, ${ }^{1}$ X. Y. Lan, ${ }^{2}$ Q. J. Zhao, ${ }^{1}$ W. J. Guan, ${ }^{1}$ and Y. H. Ma ${ }^{1}$ \\ ${ }^{1}$ Institute of Animal Sciences, Chinese Academy of Agricultural Sciences, Beijing 100193, China \\ ${ }^{2}$ College of Animal Science and Technology, Northwest A \& F University, Shaanxi Key Laboratory of Molecular Biology for Agriculture, \\ Yangling, Shaanxi 712100, China
}

Correspondence should be addressed to W. J. Guan; weijunguan301@gmail.com and Y. H. Ma; yuehui_ma@hotmail.com

Received 3 July 2013; Accepted 26 August 2013

Academic Editor: Kotaro Kitaya

Copyright ( 2013 P. F. Hu et al. This is an open access article distributed under the Creative Commons Attribution License, which permits unrestricted use, distribution, and reproduction in any medium, provided the original work is properly cited.

\begin{abstract}
Chemokines were a major regulator of body's inflammatory and immune responses. In this study, the cDNA fragment of chemokine CXC ligand 10 (CXCL10) was cloned from the Ujumqin sheep ear marginal tissue cDNA expression library; the CXCL10 gene had 103 amino acids and a molecular weight of $11.47 \mathrm{kDa}$, and it shared a high homology among cattle, sheep, and goat, while a low homology compared with mouse. The CXCL10 protein had 4 conservative cysteine residues, located in $28,30,55$, and 72 sites. The expression pattern and intracellular distribution of recombinant CXCL10 proteins in Ujumqin sheep fibroblast cells showed that there were green fluorescence signals both in cytoplasm and nucleolus after $24 \mathrm{~h}$ of transfection, the number of positive cells was increased with time, the peak level of fluorescence signal was reached after $48 \mathrm{~h}$ of transfection and the transfection efficiency was $33.3 \%$; there was a significant decrease in fluorescence intensity after $72 \mathrm{~h}$ of transfection. Expression of recombinant CXCL10 gene in Escherichia coli had a time- and temperature-dependency on the amount of protein expression, and a small quantity of inducer was needed.
\end{abstract}

\section{Introduction}

Ujumqin sheep, a larger version of the Mongolian, was found in Inner Mongolia, China. These sheep have a type of coarse wool commonly called "carpet wool" and have an ability to deposit fat in the tail; thus, they could adapt to the unfavourable local environmental conditions of the north and northwest pastoral grasslands. In the year of 2000, they were listed as one of the 78 nationally protected domestic animals by the Chinese government.

In the past years, tremendous success was achieved with the molecular genetics study of sheep [1-3]. Recently, functional gene study became one of the hottest issues $[4,5]$. Our group have been engaged in the study of molecular mechanism on the growth and development of sheep for many years; a series of genes were found, such as NADH dehydrogenase subunit 2(ND2), subunit 4 (ND4) [6], TSK21 [7], cytochrome c oxidase subunit VIa polypeptide 1-like gene (NCBI Accession no. GU585577); now we are paying more attention to chemokines of Ujumqin sheep because of their multiple biological functions especially in the mechanism of development, prevention and treatment of disease.

Chemokines were a superfamily of proteins with low molecular weight $(8-15 \mathrm{kD})$, composed of 70-90 amino acids with homology of $20-70 \%$ among different species, and had 4 conservative cysteine residues. Chemokines could selectively attract and activate leukocytes and a variety of other types of cells. They still played a role in the process of infection, directional migration, and differentiation of immune cells. Chemokines were a major regulator of body's inflammatory and immune responses; they were also involved in dendritic cell maturation, macrophage activation, and neutrophil degranulation [8]. According to the number and arrangement of N-terminal conserved cysteine, chemokines could be divided into CXC, CC, C, and CX3C families [9]; they could also be divided into ELR and non-ELR types based on the existence of ELR (glutamic acid, Leucine, and Arginine) in the protein constitution.

Chemokine CXC ligand 10 (CXCL10) was a member to CXC family, also known as interferon-inducible protein 
10 (IP-10), CXCL10 was a $10 \mathrm{kDa}$ protein which could selectively attract and activate lymphocytes, and CXCL10 binded to the receptor CXCR3 and regulated immune responses through the activation and recruitment of leukocytes, such as $\mathrm{T}$ cells, eosinophils, and monocytes [10]. Obviously, the further study on the CXCL10 gene had important significance in understanding the mechanism of development, gene function, and prevention and treatment of disease, that was also the main purpose of this study.

The cDNA library construction and analysis were considered to be an indispensable tool for functional genomic analysis as it provided much more detailed information on the genomic mechanisms underlying diverse processes of the organism [11]. The SMART technique provided a method for producing high-quality and full-length cDNA libraries that preserved the complete $5^{\prime}$ terminal sequence of mRNA [12]. Construction of Ujumqin sheep cDNA library for the protection of genetic resources as well as study of gene function had an important genetic significance. Construction of cDNA expression library could not only protect endangered treasure of biological resources, but also provide molecular markers linkage map of the building used by probes; more importantly, cDNA expression library could be used to separate full-length genes and then to carry out gene function study. At present, the sequence information of CXCL10 gene for human [13], mouse [14], cattle [15], sheep [16], goat [17], and pig [18] had been reported. However, CXCL10 gene from the Ujumqin sheep had not been reported, especially in aspect of in vitro expression characteristics.

Full-length cDNA sequence of CXCL10 was usually obtained using the rapid amplification of cDNA ends (RACE) method $[19,20]$. In this study, the cDNA of CXCL10 gene was amplified from the Ujumqin sheep ear marginal tissue cDNA expression library; then the sequence characteristics, structure, and homology of the protein encoded by the cDNA were analyzed; it was carried out to evaluate in vitro expression characteristics of CXCL10 gene from Ujumqin sheep. This study could provide scientific data and means for postulating the immune mechanism, disease resistance research, and the development of functional genes from the Ujumqin sheep.

\section{Materials and Methods}

2.1. Animals and cDNA Expression Library Construction. All procedures involving animals were approved by the animal care and use committee at the institution where the experiment was conducted. All procedures involving animals were approved and authorized by the Chinese Ministry of Agriculture.

Ear margin tissue samples were collected from Ujumqin sheep at the Conservation Center of Institute of Animal Sciences, Chinese Academy of Agricultural Sciences (Beijing, China). The samples were frozen in liquid nitrogen and then used for RNA isolation. cDNA expression library was constructed using SMART technology (SMART cDNA Library Construction Kit, Clontech); titer of the unamplified library, percentage of recombinant clone, and titer of the amplified library were determined subsequently.

2.2. Cloning of CXCL10 Gene by Screening of the cDNA Expression Library. CXCL10 gene was obtained by screening of the cDNA expression library using PCR method. The PCR primers were designed by Primer Premier 5.0, based on the mRNA sequence of CXCL10 gene from Ovis aries (NM 001009191.1); the specific primers of cDNA sequence were as follows:

\section{P1: 5' -TGCAGCACCATGAACAAAAT-3', P2: 5'-GTGATTATGCCTCTTTCTGTGTTC-3' .}

The PCR products were cloned into TA-cloning vector pGEM-T Easy (Promega). Plasmid DNA was sequenced by Huada Zhongsheng Scientific Corporation (Beijing, China).

2.3. Overexpression of Recombinant CXCL10 Gene in Fibroblast Cells. The DNA fragment of CXCL10 gene was flanked with Xho I and BamH I sites; after double digestion, the final fragment was inserted into pEGFP-N3 vector (Clontech) for transfection.

Ujumqin sheep fibroblast line which has been established in our laboratory was used as target cells [21]. Cells were seeded in 24-well plates and transfected with the plasmid DNA of CXCL10 gene (pEGFP-N3-CXCL10) by Lipofectamine 2000 (Invitrogen). The medium was refreshed $6 \mathrm{~h}$ after transfection, and cells were observed 24, 48, and $72 \mathrm{~h}$ after transfection using Nikon TE-2000-E inverted confocal microscope with excitation wavelengths of $488 \mathrm{~nm}$ to determine the transfection efficiency and morphology of positive cells. For each experimental group, images were captured from 10 visual fields to determine the total and positive cell counts in each field for the calculation of transfection efficiencies.

\subsection{Expression Characteristics of Recombinant CXCL10 Gene} in Escherichia coli. The DNA fragment of CXCL10 gene was flanked with BamH I and Xho I sites; after double digestion, the final fragment was inserted into pGEX-4T-1 vector (GE Healthcare) for protein expression.

The constructed expression plasmid was transformed into BL21 (DE3) competent cells (Tiangen), and the recombinant protein production was carried out using autoinduction method. Briefly, proteins were expressed in cells by induction with isopropyl-1-thio- $\beta$-D-galactopyranoside (IPTG). Integrality of recombinant proteins was tested by Western blot, the expression condition was optimized, and inducer concentration, induction time, and temperature were tested respectively, for high-level protein expression [22]. The results were confirmed using SDS-PAGE.

2.5. Data Analysis. Homology study of the Ujumqin sheep CXCL10 gene compared with the gene sequences of other species was performed using Blast 2.1 (http://www.ncbi .nlm.nih.gov/blast/). ORF of the DNA sequence was searched using ORF finder software (http://www.ncbi.nlm.nih.gov/ gorf/gorf.html). The values of WM and pI were computed 


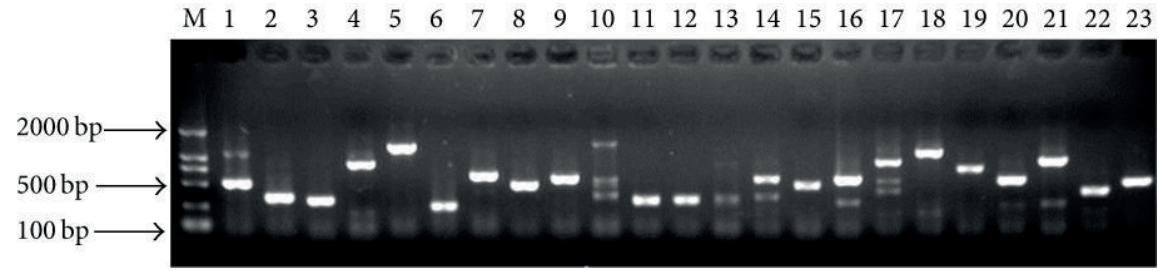

FIgURE 1: PCR products of the random clones. M: $2000 \mathrm{bp}, 1-23:$ cDNA fragment.

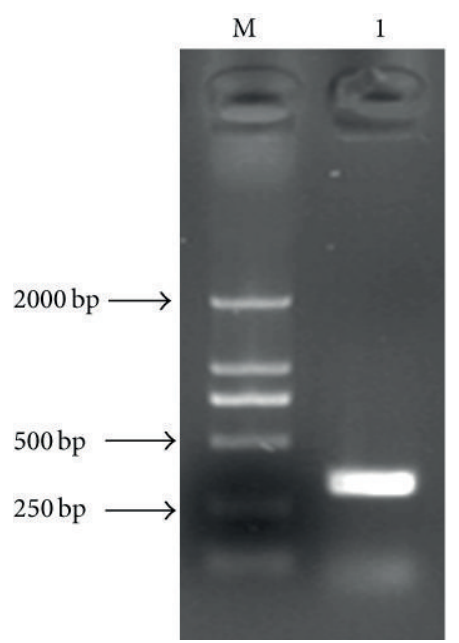

Figure 2: PCR products of the Ujumqin sheep CXCL10 gene. M: molecular marker DL2000, 1: amplified CXCL10 gene.

using the Compute pI/Mw tool (http://www.expasy.org/ tools/pi_tool.html). Protein structure of the CXCL10 gene sequence cloned was analyzed using PredictProtein software (http://emboss.bioinformatics.nl/cgi-bin/emboss). Multiple sequence alignment was performed by software DNAstar Lasergene and DNAMAN 6.0.

\section{Results and Analysis}

3.1. Amplification and Detection of the Constructed cDNA Expression Library. Titers of the unamplified and amplified library were determined by counting the number of colonies according to the protocol of cDNA Library Construction Kit; the results showed that unamplified and amplified library had a titer of $8.24 \times 10^{6} \mathrm{pfu} / \mathrm{mL}$ and $1.60 \times 10^{10} \mathrm{pfu} / \mathrm{mL}$, respectively. To test for ligation efficiency in the amplified library, the percentage of recombinant clones was determined by screening $96 \mathrm{cDNA}$ inserts using PCR method; the results showed that the ligation of the cDNA to the $\lambda$ TriplEx 2 Vector was $93.75 \%$ recombinants, and the average length of cDNA inserts was $1.0 \mathrm{~kb}$ (Figure 1). The full-length cDNA library constructed from Ujumqin sheep conformed to the requirements of a standard library [23].

3.2. Analysis of the cDNA of CXCL10 Gene from Ujumqin Sheep. The cDNA fragment with $309 \mathrm{bp}$ in size was amplified from the cDNA expression library (Figure 2). On the basis of the high identity, it was concluded that the cDNA isolated was the cDNA encoding the Ujumqin sheep CXCL10 gene. The CXCL10 gene sequence was submitted to Genbank (Accession no. HM017954).

As determined by homology analysis, the nucleotide sequence of CXCL10 gene cloned from the Ujumqin sheep shared a homology with those of human, mouse, cattle, sheep, goat, and pig of $77.46 \%, 70.48 \%, 96.76 \%, 100 \%, 98.71 \%$, and $87.94 \%$, respectively (see Figure S1a in Supplementary material available online at http://dx.doi.org/10.1155/2013/217942); the homologies for amino acid sequences were $84.62 \%$, $80.77 \%, 99.02 \%, 100 \%, 99.02 \%$, and $93.27 \%$, respectively (Figure S1b). It was indicated that CXCL10 gene shared a high homology among cattle, sheep, and goat; there was also a high homology of sheep compared with human and pig, while homology between sheep and mouse was the lowest.

\subsection{Prediction and Analysis of Primary Structure, Protein} Functional Sites, and Advanced Structure in CXCL10 of the Ujumqin Sheep. Primary structure analysis revealed that the molecular weight of the putative CXCL10 protein of the Ujumqin sheep was $11.47 \mathrm{kDa}$ with a theoretical pI 10.20. Like most chemokines, CXCL10 protein of the Ujumqin sheep had 4 conservative cysteine residues, located in $28,30,55$, and 72 sites, in which the first 2 cysteine residues were separated by threonine (Figure S2); it was demonstrated that the sequence characteristics of CXCL10 gene which we cloned from Ujumqin sheep were accordant with the members to CXC family. While the highest content is the Leu residues (11.77\%), far higher than other amino acids and without Asp, His, Trp, and Tyr residues (Figure S3), it was indicated that Ujumqin sheep CXCL10 protein was ELR type based on the existence of ELR (glutamic acid, Leucine, and Arginine) in the protein constitution. The secondary structure analysis of CXCL10 protein indicated that the protein was 39.5\% in helix, $18.6 \%$ in sheet, $39.5 \%$ in turns, and $20.9 \%$ in coil.

The water unsoluble property of CXCL10 protein limits its isolation, purification, and crystal growth, so it was difficult to determine the structure of CXCL10 protein. Transmembrane helices prediction was an important application in bioinformatics. In this study, tmap in the EMBOSS database and TMHMM 2.0 were comprehensively used in the prediction of transmembrane domain of CXCL10 protein. The result showed that high hydrophobicity occurred in the first 28 residues, indicating a probable transmembrane domain (Figure $\mathrm{S} 4 \mathrm{a}$ ).

Signal peptide located in the N-terminus of secretory protein, and there was approximately 20 residues signal 


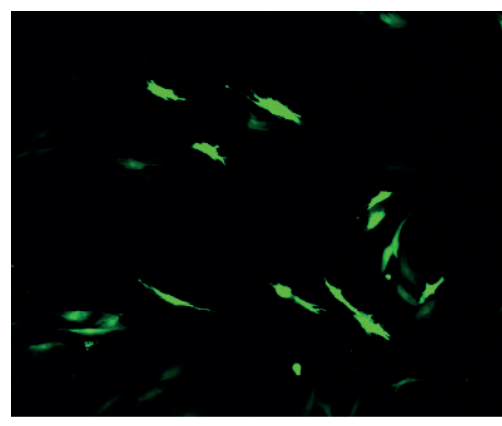

(a)

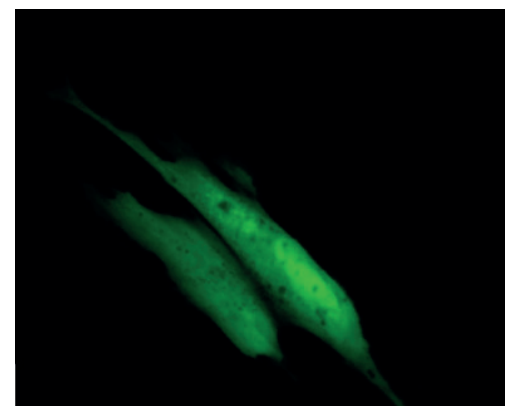

(d)

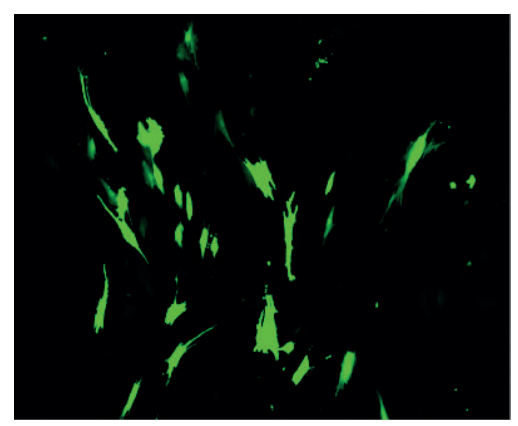

(b)

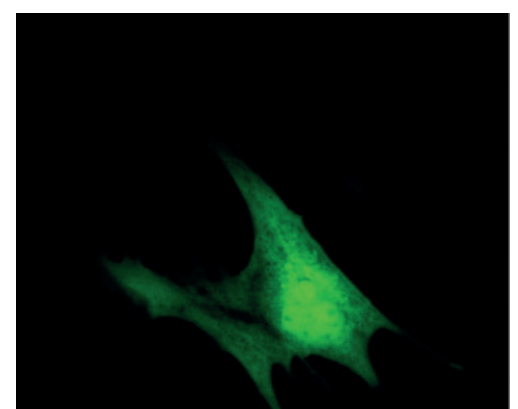

(e)

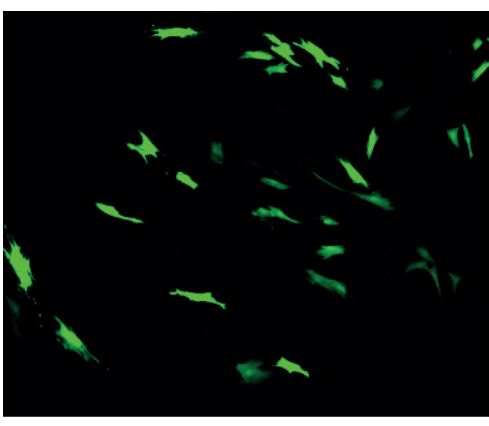

(c)

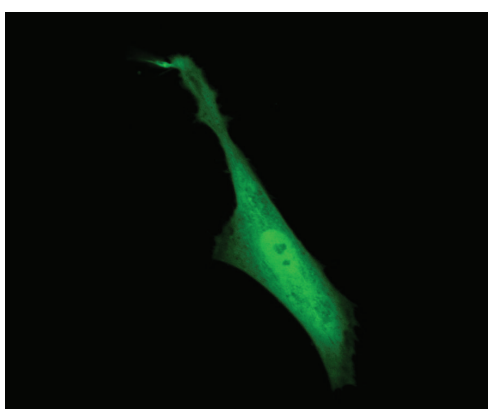

(f)

FIGURE 3: Transfection of recombinant pEGFP-N3-CXCL10 in Ujumqin sheep fibroblast cells. (a), (b), (c) Transfection after $24 \mathrm{~h}, 48 \mathrm{~h}$, and $72 \mathrm{~h}$, respectively (100x). (d), (e), (f) Transfection after $24 \mathrm{~h}, 48 \mathrm{~h}$, and $72 \mathrm{~h}$, respectively (400x).

peptides in a typical chemokine; in this study, signal peptide position and cleavage site of CXCL10 protein of Ujumqin sheep were predicted by SignalP 2.0, the signal peptide of CXCL10 protein was consisted of a positive charge region, a hydrophobic region, and a polar region (Figure S4b), prediction of cleavage site was evaluated by Y-score maximum, the result showed that cleavage site of CXCL10 protein was between pos. 19 and 20, and mean S-score in pos. 1-19 was 0.928 ; it could be indicated that CXCL10 protein was secretory protein, and there was a signal peptide sequence in the N-terminal of CXCL10 protein.

In most cases, two pairs of double sulfur bands consisted by 4 conservative cysteine residues formed special structure of chemokine; in this study, spatial structure of CXCL10 protein of Ujumqin sheep was predicted by CPHmodels 2.0, and human [24] and mouse [25] CXCL10 protein derived from PDB protein database were taken as template; after Magic Fit by Swiss-PdbViewer4.0, the result showed that the spatial structure of CXCL10 protein was accordant with secondary structure predicted by garnier. Ujumqin sheep CXCL10 protein had similar structure with human, while different from mouse (Figure S5).

Topology prediction showed that there was a small cytokines $\mathrm{C}-\mathrm{x}-\mathrm{C}$ subfamily signature in the CXCL10 protein of Ujumqin sheep; these small cytokines were also called intercrines or chemokines. They were cationic proteins of 70100 amino acid residues that shared four conserved cysteine residues involved in two disulfide bonds. There was also two N-glycosylation sites, one $\mathrm{N}$-myristoylation site, two Casein kinase II phosphorylation sites, and five protein kinase C phosphorylation sites in the CXCL10 protein of Ujumqin sheep (Figure S6).

3.4. Overexpression of Recombinant CXCL10 Gene in Fibroblast Cells. The expression pattern and intracellular distribution of recombinant CXCL10 protein in Ujumqin sheep fibroblast cells were analyzed after transfection with the plasmid pEGFP-N3-CXCL10. pEGFP-N3 encodes a red-shifted variant of wild-type GFP which has been optimized for brighter fluorescence and higher expression in somatic cells of livestock and poultry, which had been demonstrated in our early studies $[26,27]$. CXCL10 gene cloned into the MCS could be expressed as fusions to the $\mathrm{N}$ terminus of EGFP.

In the initial stage of transfection, the majority of the cells had no significant change in morphology; some of the cells were shrinking and the number of live cells was decreased to some extent, there were green fluorescence signals both in the cytoplasm and nucleolus of transfected cells after $24 \mathrm{~h}$ (Figure 3(a)), the number of positive cells was increased with time, and they reached the peak level after $48 \mathrm{~h}$ of transfection (Figure 3(b)). The transfection efficiency was $33.3 \%$; there was a significant decrease in fluorescence intensity after $72 \mathrm{~h}$ of transfection (Figure 3(c)). Fluorescence intensity was stronger in nucleolus than in cytoplasm during the transfection (Figures 3(d), 3(e), and 3(f)). The high level of recombinant CXCL10 gene expression in fibroblast cells could last for 1 week, indicating that gene duplication, transcription, protein synthesis, and modification were highly effective in transfected cells, and there was no significant effects of recombinant proteins on cell growth and proliferation. 
3.5. Expression of Recombinant CXCL10 Gene in Escherichia coli. There was target protein expression after $6 \mathrm{~h}$ induction by $1 \mathrm{mmol} / \mathrm{L}$ IPTG and molecular weight of target protein was $37.47 \mathrm{kD}$. GST occurred naturally as a $26 \mathrm{kDa}$ protein that could be expressed in E. coli with full enzymatic activity, while CXCL10 protein had a molecular weight of $11.47 \mathrm{kDa}$. Fusion proteins that possess the complete amino acid sequence of GST also demonstrated GST enzymatic activity and could undergo dimerization similar to that observed in nature; it was concluded that the recombinant protein was CXCL10 protein after Western blot analysis (data were not shown).

Yield of fusion protein was highly variable and was affected by the nature of the fusion protein, the host cell, and the culture conditions used during the optimization of expression conditions. In this study, samples from evaluations of media, growth temperature, culture density, induction conditions, and other variables were processed successively.

Protein expression was increased with temperature rising: the highest amount of protein expression appeared at the temperature of 37 degrees; then the yield of recombinant protein decreased as the temperature raised to 40 degrees (data were not shown). When the IPTG concentration was $0.1-2.0 \mathrm{mmol} / \mathrm{L}$, there was no significant change in recombinant CXCL10 protein expression under 37-degree induction (Figure 4(a)). It was concluded that recombinant proteins were completely expressed by induction with IPTG. Without inducer, there was little recombinant protein expression. When the inducer concentration was $0.1,0.3,0.5,0.8,1.2,1.4$, and $2.0 \mathrm{mM}$, respectively, the expression of the recombinant proteins was initiated, but there were no significant changes in expression, indicating that a small quantity of inducer was needed when the protein expression was in control of the tac promoter. When the induction of recombinant CXCL10 protein was performed with the IPTG at $0.1 \mathrm{mM}$ for $0,2,4$, 6 , and $8 \mathrm{~h}$ at 37 degrees, respectively, protein expression was increased with induction time (Figure 4(b)).

In summary, the optimal inducer concentration for the expression of recombinant CXCL10 protein was $0.1 \mathrm{mM}$, the optimum induction time was $8 \mathrm{~h}$, and the highest amount of protein expression was achieved at 37 degrees.

\section{Discussion}

4.1. Cloning of CXCL10 Gene from SMART cDNA Library of the Ujumqin Sheep. The SMART library provided a useful resource for the functional genomic study of Ujumqin sheep and could present some new molecular material for this species as well. In this study, the results indicated that the length of CXCL10 fragment cloned from cDNA library was $309 \mathrm{bp}$, encoding 103 amino acids, with a molecular weight of $11.47 \mathrm{kDa}$. Like most chemokines, CXCL10 protein of the Ujumqin sheep had 4 conservative cysteine residues; CXCL10 gene which we cloned from Ujumqin sheep was accordant with the members to CXC family.

Bioinformatical analysis of CXCL10 gene was required, which could provide more valuable information in further studies; for example, basic information could be illustrated by DNA chromosome location, introns/exons, and ORF

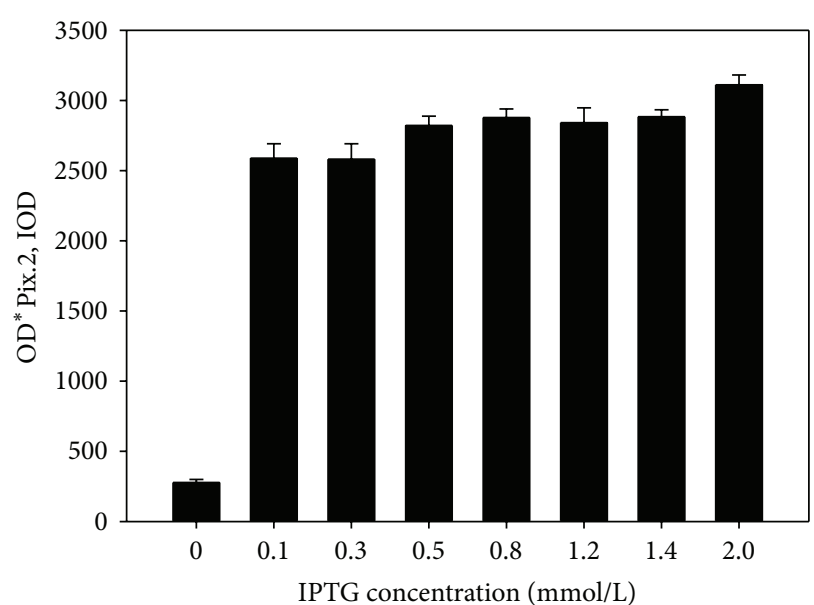

(a)

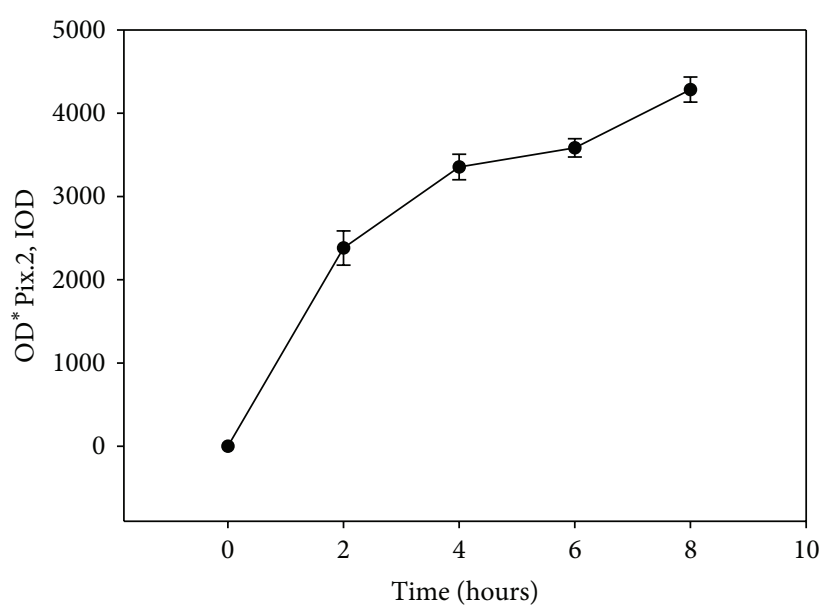

(b)

Figure 4: Effect of IPTG concentration and induction time on recombinant protein expression. (a) Protein expression with different IPTG concentrations, (b) protein expression with different induction time.

analysis; gene regulation mechanism could be identified by prediction of promoter, CpG island, and transcription factor analysis; characteristics of gene encoding protein could be determined by main properties, subcellular localization, and antigenic sites analysis; gene functions could be further determined by similarity search, function sites, and structure analysis. It was reported that porcine CXCL10 protein has high homology with the CXCL10 of five species-dog $(87 \%)$, human $(84 \%)$, monkey (84\%), mouse $(75 \%)$, and rat $(70 \%)$; the phylogenetic tree analysis revealed that the swine CXCL10 had a closer genetic relationship with the CXCL10 of dog than with those of human, monkey, mouse, and rat [28]. In this study, the nucleotide sequence of CXCL10 gene cloned from the Ujumqin sheep shared a homology with those of human, mouse, cattle, sheep, goat, and pig of $77.46 \%$, $70.48 \%, 96.76 \%, 100 \%, 98.71 \%$, and $87.94 \%$, respectively; the homologies for amino acid sequences were $84.62 \%, 80.77 \%$, 99.02\%, 100\%, 99.02\%, and 93.27\%, respectively. Alignment analysis indicated that CXCL10 gene shared a high homology 
among cattle, sheep, and goat; there was also a high homology of sheep compared with human and pig, while homology between sheep and mouse was the lowest.

\subsection{Overexpression of Recombinant CXCL10 Gene in Ujumqin} Sheep Fibroblast Cells. Previous studies had demonstrated that the overexpression of CXCL10 in cancer or tumor cells inhibited cell proliferation of the transfected cells; for example, Nagpal studied the effects of overexpression of CXCL10 in human prostate cancer LNCaP cells. LNCaP cells were transiently transfected with CXCL10 cDNA in pIRES2-EGFP vector, and overexpression of CXCL10 inhibited cell proliferation of the transfected cells by $30 \%-40 \%$ [29]; another study showed that overexpression of CXCL10 inhibited StAR D1 expression, decreased progesterone synthesi, and inhibited cell proliferation of mouse Leydig tumor cell [30], while in our study, it was found that there was no significant effect on the proliferation of Ujumqin sheep fibroblast cells; a possible explanation was that the mechanism of CXCL10 was different in some cell types.

In the study of Zhao et al. [31], the amplified CXCL10 gene was inserted into the eukaryotic expression vector pcDNA3.1(+), and the recombinant expression vector pcDNA3.1(+)-IP-10 was transfected into NIH 3T3 cells via liposome. The method was accordant with our study, while the cell types were different from our study, and the transfection efficiency was not illustrated. So more details on the in vitro expression characteristics of CXCL10 need to be studied. In this study, the CXCL10 gene could be effectively expressed in fibroblast cells. The expression pattern and intracellular distribution of recombinant CXCL10 proteins in Ujumqin sheep fibroblast cells were analyzed after transfection with the plasmid pEGFP-N3-CXCL10. There were green fluorescence signals both in cytoplasm and nucleolus of transfected cells after $24 \mathrm{~h}$, the number of positive cells was increased with time, and they reached the peak level after $48 \mathrm{~h}$ of transfection; there was a significant decrease in fluorescence intensity after $72 \mathrm{~h}$ of transfection. The transfection efficiency was $22.8 \%$; fluorescence intensity was stronger in nucleolus than in cytoplasm during the transfection.

\subsection{Expression of Recombinant CXCL10 Gene in Escherichia} coli. The lack of immunological reagents for some experimental animals prompted the clone of CXCL10 and the expression of the gene as a recombinant protein. Danesh had cloned and sequenced the genes encoding ferret CXCL10 and then cloned into the pcDNA3.1/His6.V5/TOPO expression vector; recombinant ferret CXCL10 protein was expressed and purified using COS-7 cells [32]. In this study, the DNA fragment of CXCL10 gene was inserted into pGEX-4T-1 vector for protein expression; the pGEX-4T-1 vector was designed for inducible, high-level intracellular expression of genes or gene fragments as fusions with Schistosoma japonicum GST [33]. Expression pattern of recombinant CXCL10 gene in Escherichia coli was different with induction temperature, inducer concentration, and induction time; the data showed that the recombinant CXCL10 had a time- and temperature-dependency on the amount of protein expression. The data also indicated that a small quantity of inducer was needed when the protein expression was in control of the tac promoter.

Consequently, analysis of the expression of CXCL10 combined with the knowledge of their functions could facilitate the understanding and allow us to take a glimpse of the overall picture of CXCL10 gene in Ujumqin sheep. The findings could give scientific support and orientation for postulating the immune mechanism, disease resistance research, and the development of functional genes from the Ujumqin sheep.

\section{Authors' Contribution}

P. F. Hu and X. C. Li contributed equally to this study.

\section{Acknowledgments}

This research was funded by the Transgenic Research Program of China (2013ZX08009-003-006, 2013ZX08012-00206), National Nature Science Foundation of China (31201765, 31272403), the Agricultural Science and Technology Innovation Program of China, and the earmarked fund for Modern Agro-Industry Technology Research System (nycytx-40-01).

\section{References}

[1] M. X. Chu, J. Yang, T. Feng et al., "GDF9 as a candidate gene for prolificacy of Small Tail Han sheep," Molecular Biology Reports, vol. 38, no. 8, pp. 5199-5204, 2011.

[2] M. X. Chu, X. C. Wang, M. Jin et al., "DNA polymorphism of $5^{\prime}$ flanking region of prolactin gene and its association with litter size in sheep," Journal of Animal Breeding and Genetics, vol. 126, no. 1, pp. 63-68, 2009.

[3] M. X. Chu, Z. H. Liu, C. L. Jiao et al., "Mutations in BMPR-IB and BMP-15 genes are associated with litter size in Small Tailed Han sheep (Ovis aries)," Journal of Animal Science, vol. 85, no. 3, pp. 598-603, 2007.

[4] J. N. He, B. Y. Zhang, M. X. Chu et al., "Polymorphism of insulin-like growth factor 1 gene and its association with litter size in Small Tail Han sheep," Molecular Biology Reports, vol. 39, no. 10, pp. 9801-9807, 2012.

[5] M. X. Chu, X. H. Guo, C. J. Feng et al., "Polymorphism of 5' regulatory region of ovine FSHR gene and its association with litter size in Small Tail Han sheep," Molecular Biology Reports, vol. 39, no. 4, pp. 3721-3725, 2012.

[6] J. Guo, L.-X. Du, Y.-H. Ma et al., "A novel maternal lineage revealed in sheep (Ovis aries)," Animal Genetics, vol. 36, no. 4, pp. 331-336, 2005.

[7] X. Wang, Y. H. Ma, H. Chen, and W. J. Guan, "Genetic and phylogenetic studies of Chinese native sheep breeds (Ovis aries) based on mtDNA D-loop sequences," Small Ruminant Research, vol. 72, no. 2-3, pp. 232-236, 2007.

[8] P. A. Ruffini, P. Morandi, N. Cabioglu, K. Altundag, and M. Cristofanilli, "Manipulating the chemokine-chemokine receptor network to treat cancer," Cancer, vol. 109, no. 12, pp. 23922404, 2007.

[9] M. D. Krathwohl and J. L. Anderson, "Chemokine CXCL10 (IP-10) is sufficient to trigger an immune response to injected antigens in a mouse model," Vaccine, vol. 24, no. 15, pp. 29872993, 2006. 
[10] A. Antonelli, P. Fallahi, M. Rotondi et al., "Increased serum CXCL10 in Graves' disease or autoimmune thyroiditis is not associated with hyper- or hypothyroidism per se, but is specifically sustained by the autoimmune, inflammatory process," European Journal of Endocrinology, vol. 154, no. 5, pp. 651-658, 2006.

[11] Z.-T. Shao, X. Cong, J.-D. Yuan et al., "Construction and characterization of a cDNA library from head kidney of Japanese sea bass (Lateolabrax japonicus)," Molecular Biology Reports, vol. 36, no. 7, pp. 2031-2037, 2009.

[12] C.-Q. Liu, T.-F. Lu, B.-G. Feng, D. Liu, W.-J. Guan, and Y.-H. $\mathrm{Ma}$, "Construction of cDNA library and preliminary analysis of expressed sequence tags from siberian tiger," International Journal of Biological Sciences, vol. 6, no. 6, pp. 584-589, 2010.

[13] A. D. Luster, S. C. Jhanwar, and R. S. K. Chaganti, "Interferoninducible gene maps to a chromosomal band associated with a $(4 ; 11)$ translocation in acute leukemia cells," Proceedings of the National Academy of Sciences of the United States of America, vol. 84, no. 9, pp. 2868-2871, 1987.

[14] Y. Ohmori and T. A. Hamilton, "A macrophage LPS-inducible early gene encodes the murine homologue of IP-10," Biochemical and Biophysical Research Communications, vol. 168, no. 3, pp. 1261-1267, 1990.

[15] A. Taubert, H. Zahner, and C. Hermosilla, "Dynamics of transcription of immunomodulatory genes in endothelial cells infected with different coccidian parasites," Veterinary Parasitology, vol. 142, no. 3-4, pp. 214-222, 2006.

[16] K. Nagaoka, A. Sakai, H. Nojima et al., "A chemokine, interferon (IFN)- $\gamma$-inducible protein $10 \mathrm{kDa}$, is stimulated by IFN- $\tau$ and recruits immune cells in the ovine endometrium," Biology of Reproduction, vol. 68, no. 4, pp. 1413-1421, 2003.

[17] K. Nagaoka, H. Nojima, F. Watanabe et al., "Regulation of blastocyst migration, apposition, and initial adhesion by a chemokine, interferon $\gamma$-inducible protein $10 \mathrm{kDa}$ (IP-10), during early gestation," Journal of Biological Chemistry, vol. 278, no. 31, pp. 29048-29056, 2003.

[18] J. Yang, I. Choi, S. D. Kim et al., "Molecular characterization of cDNA encoding porcine IP-10 and induction of porcine endothelial IP-10 in response to human TNF- $\alpha$, Veterinary Immunology and Immunopathology, vol. 117, no. 1-2, pp. 124-128, 2007.

[19] Y.-Z. Cheng, R.-X. Wang, and T.-J. Xu, "Molecular cloning, characterization and expression analysis of a miiuy croaker (Miichthys miiuy) CXC chemokine gene resembling the CXCL9/CXCL10/CXCL11," Fish and Shellfish Immunology, vol. 31, no. 3, pp. 439-445, 2011.

[20] G. Y. Liu and Y. Z. Xiong, "Isolation, sequence analysis and expression profile of a novel porcine gene, CXCL10, differentially expressed in the Longissimus dorsi muscle tissues from Meishan, Meishan $\times$ Large White cross and Large White pigs," Mitochondrial DNA, vol. 18, no. 6, pp. 415-422, 2007.

[21] R. S. Na, Q. J. Zhao, D. P. Jin et al., "Establishment and biological characteristics of Ujumqin sheep fibroblast line," Cytotechnology, vol. 62, no. 1, pp. 43-52, 2010.

[22] P. F. Hu, W. J. Guan, X. C. Li, and Y. H. Ma, "Construction of recombinant proteins for reprogramming of endangered Luxi cattle fibroblast cells," Molecular Biology Reports, vol. 6, pp. 7175-7182, 2012.

[23] S.-Y. Ying, "Complementary DNA libraries: an overview," Applied Biochemistry and Biotechnology B, vol. 27, no. 3, pp. 245252, 2004.
[24] G. J. Swaminathan, D. E. Holloway, R. A. Colvin et al., "Crystal structures of oligomeric forms of the IP-10/CXCL10 chemokine," Structure, vol. 11, no. 5, pp. 521-532, 2003.

[25] T. Jabeen, P. Leonard, H. Jamaluddin, and K. R. Acharya, "Structure of mouse IP-10, a chemokine," Acta Crystallographica D, vol. 64, no. 6, pp. 611-619, 2008.

[26] H. Wu, W. Guan, H. Li, and Y. Ma, "Establishment and characteristics of white ear lobe chicken embryo fibroblast line and expression of six fluorescent proteins in the cells," Cell Biology International, vol. 32, no. 12, pp. 1478-1485, 2008.

[27] X. C. Li, H. Yue, C. Y. Li et al., "Establishment and characterization of a fibroblast cell line derived from Jining Black Grey goat for genetic conservation," Small Ruminant Research, vol. 87, no. 1-3, pp. 17-26, 2009.

[28] G. Y. Liu and Y. Z. Xiong, "Isolation, sequence analysis and expression profile of a novel porcine gene, CXCL10, differentially expressed in the Longissimus dorsi muscle tissues from Meishan, Meishan $\times$ Large White cross and Large White pigs," Mitochondrial DNA, vol. 18, no. 6, pp. 415-422, 2007.

[29] M. L. Nagpal, J. Davis, and T. Lin, "Overexpression of CXCL10 in human prostate $\mathrm{LNCaP}$ cells activates its receptor (CXCR3) expression and inhibits cell proliferation," Biochimica et Biophysica Acta, vol. 1762, no. 9, pp. 811-818, 2006.

[30] M. L. Nagpal, Y. Chen, and T. Lin, "Effects of overexpression of CXCL10 (cytokine-responsive gene-2) on MA-10 mouse Leydig tumor cell steroidogenesis and proliferation," Journal of Endocrinology, vol. 183, no. 3, pp. 585-594, 2004.

[31] Y.-J. Zhao, Y. Lin, M.-Y. Li, H. Li, and Z.-H. Jiang, "Construction of a eukaryotic expression vector of the gene encoding rat interferon-gamma-inducible protein and its expression in NIH 3T3 cells," Nan Fang Yi Ke Da Xue Xue Bao, vol. 29, no. 4, pp. 615-618, 2009.

[32] A. Danesh, C. Seneviratne, C. M. Cameron et al., "Cloning, expression and characterization of ferret CXCL10," Molecular Immunology, vol. 45, no. 5, pp. 1288-1297, 2008.

[33] D. B. Smith and K. S. Johnson, "Single-step purification of polypeptides expressed in Escherichia coli as fusions with glutathione S-transferase," Gene, vol. 67, no. 1, pp. 31-40, 1988. 

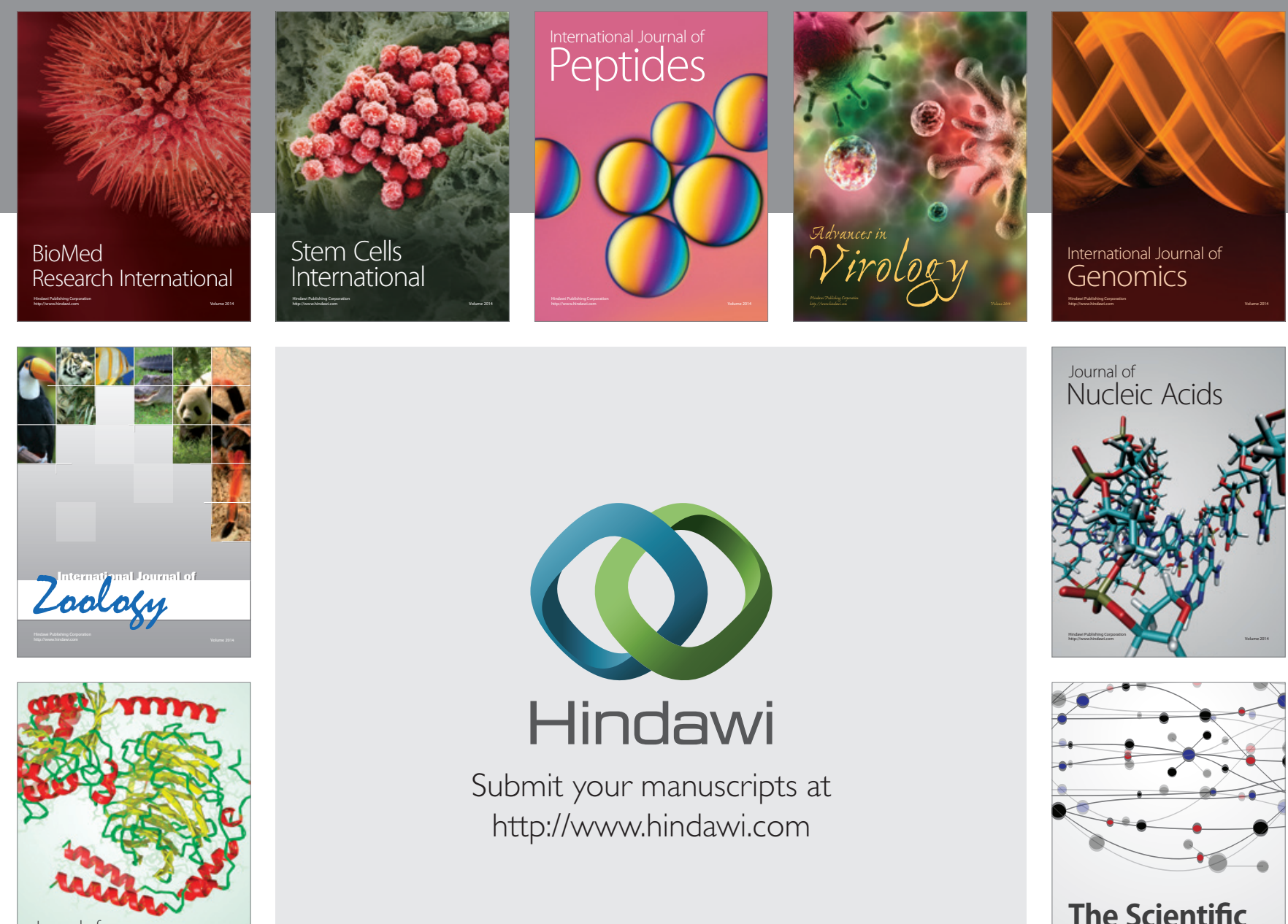

Submit your manuscripts at

http://www.hindawi.com

Journal of
Signal Transduction
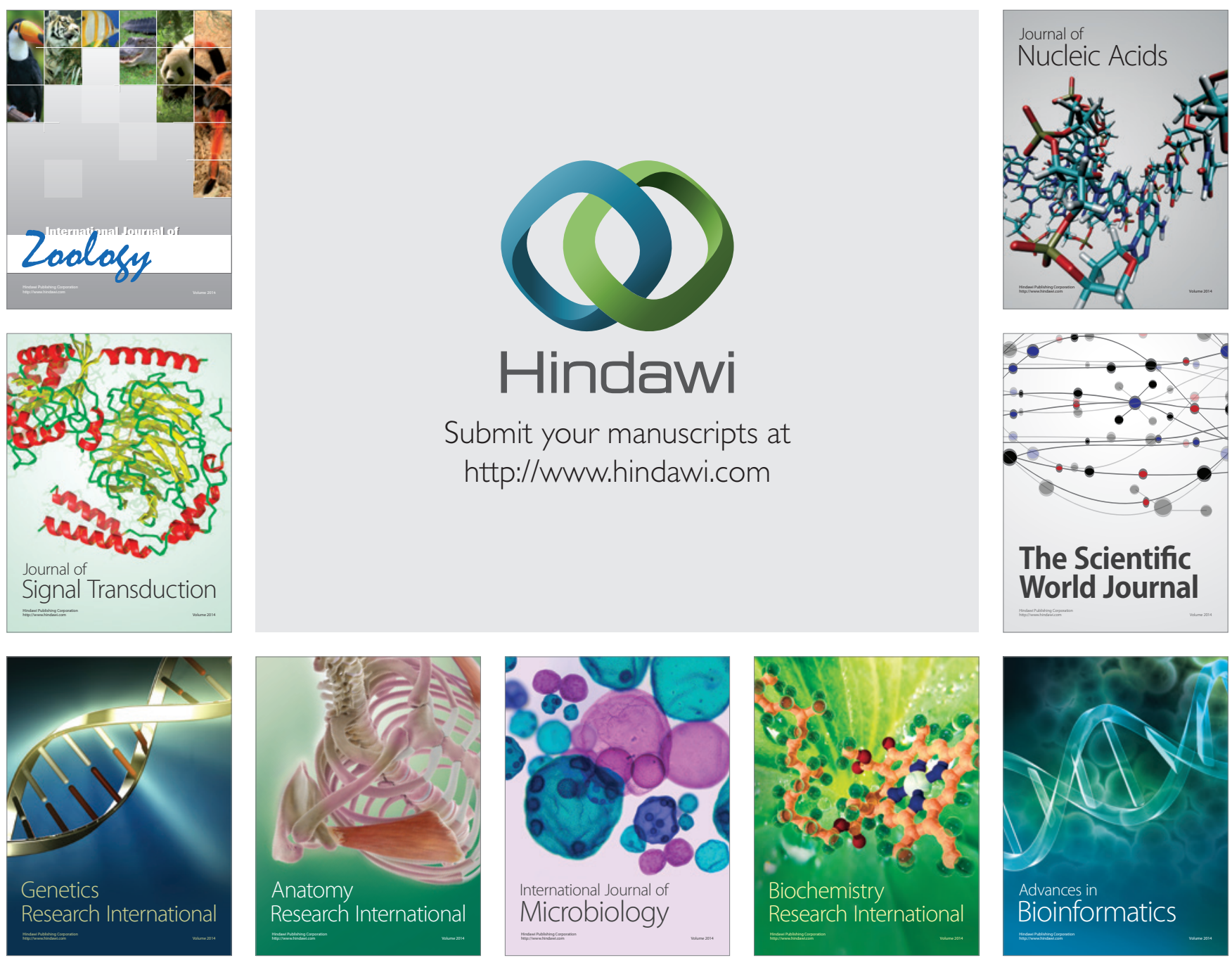

The Scientific World Journal
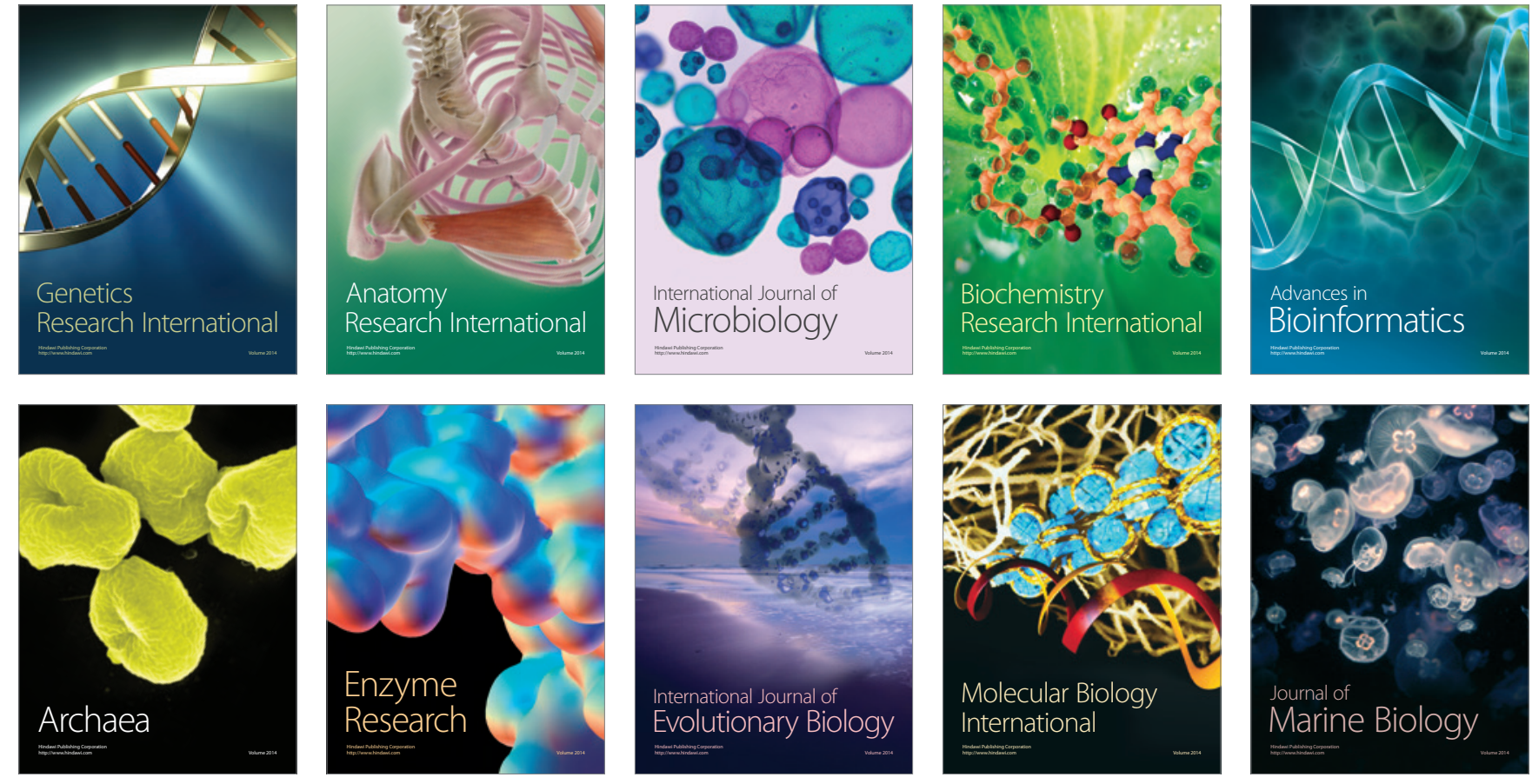